\title{
Regulation and mechanism of YAP/TAZ in the mechanical microenvironment of stem cells (Review)
}

\author{
YING LI ${ }^{1,2}$, JINMING WANG ${ }^{1,3}$ and WEILIANG ZHONG ${ }^{1,3}$ \\ ${ }^{1}$ Department of Orthopaedics Surgery, First Affiliated Hospital of Dalian Medical University, Dalian, \\ Liaoning 116011; ${ }^{2}$ Department of Clinical Laboratory, Second Affiliated Hospital of Dalian Medical University, \\ Dalian, Liaoning 116023; ${ }^{3}$ Key Laboratory of Molecular Mechanism for Repair and \\ Remodeling of Orthopaedic Diseases, Dalian, Liaoning 116011, P.R. China
}

Received October 6, 2019; Accepted February 2, 2021

DOI: $10.3892 / \mathrm{mmr} .2021 .12145$

\begin{abstract}
Stem cells receive cues from their physical and mechanical microenvironment via mechanosensing and mechanotransduction. These cues affect proliferation, self-renewal and differentiation into specific cell fates. A growing body of evidence suggests that yes-associated protein (YAP) and transcriptional coactivator with PDZ-binding motif (TAZ) mechanotransduction is key for driving stem cell behavior and regeneration via the Hippo and other signaling pathways. YAP/TAZ receive a range of physical cues, including extracellular matrix stiffness, cell geometry, flow shear stress and mechanical forces in the cytoskeleton, and translate them into cell-specific transcriptional programs. However, the mechanism by which mechanical signals regulate YAP/TAZ activity in stem cells is not fully understand. The present review summarizes the current knowledge of the mechanisms involved in YAP/TAZ regulation on the physical and mechanical microenvironment, as well as its potential effects on stem cell differentiation.
\end{abstract}

\section{Contents}

1. Introduction

2. Regulation of YAP/TAZ in mechanotransduction in stem cells

3. Mechanism of YAP/TAZ regulation

4. Conclusion

Correspondence to: Dr Weiliang Zhong, Department of Orthopaedics Surgery, First Affiliated Hospital of Dalian Medical University, 222 Zhongshan Road, Dalian, Liaoning 116011, P.R. China

E-mail: zwl8632767@163.com

Key words: yes-associated protein/transcriptional coactivator with PDZ-binding motif, stem cells, microenvironment, mechanotransduction, signaling pathway

\section{Introduction}

Stem cells are a group of progenitor cells characterized by self-renewal and differentiation ability. Within their niche or local microenvironment, stem cells communicate via physical and mechanical cues to regulate cell fate and behavior (1). Early research has focused on biochemical signals produced by chemical or solution media when discussing the molecular signaling mechanisms underlying stem cell self-renewal, growth and differentiation (2). However, it is hypothesized that cells perceive their microenvironment not only through soluble signals but also via physical and mechanical cues, such as extracellular matrix (ECM) stiffness or confined adhesiveness (3). Similar to intrinsic and extrinsic biochemical factors, mechanical cues resulting from both intracellularly generated and externally applied forces have a broad range of effects on stem cell fate. For example, MSCs have the ability to differentiate into neuroblast, chondrocyte, osteoblast, adipocytes and numerous other cell types within matrices, which mimic the stiffness of their native substrate (4-6). Also, the extracellular matrix structure such as nanotopographic structures or fluid shear stress can affect differentiation of stem cells $(7,8)$. Studies have shown that yes-associated protein/transcriptional coactivator with PDZ-binding motif (YAP/TAZ) serves an important role in biomechanical and mechanical signaling that affects self-renewal and differentiation of stem cells $(3,9)$. The present review summarizes the current knowledge of the mechanisms involved in YAP/TAZ regulation on the physical and mechanical microenvironment and its potential effects on stem cell differentiation.

\section{Regulation of YAP/TAZ in mechanotransduction in stem cells}

Stem cells are a paradigm model system in the mechanotransduction field; it has been shown that differentiation of stem cells into distinct cell fates is dictated by the physical features of the cellular microenvironment (10). Numerous studies have shown that YAP/TAZ is a key regulator of mechanical properties of the stem cell microenvironment (11-14). Various biophysical stimuli from external forces, such as cyclic stretching, shear stress and acoustic tweezing, also modulate stem cell fate via YAP/TAZ (15-18). 
Flow shear stress. Flow shear stress can be defined as a function of strain rate, which is the frictional force generated by the flow of fluid on a contact surface (19). More specifically, fluid shear stress is defined as stress (i.e., force per unit area) applied by a fluid to the tangential direction of the contact surface. Fluid shear stress serves an important role in the differentiation of embryonic and mesenchymal stem cells (MSCs) (20).

MSCs are mechanically regulated by shear stress generated in tissues by extravascular liquid flow. To date, the regulation of YAP by shear stress has rarely been characterized in the literature. YAP is regulated by fluid shear stress in osteoblasts and stem cells $(8,21)$. Zhong et al (8) found that increased YAP expression levels, triggered by flow shear stress, increased osteogenesis and decreased adipogenesis of MSCs and initiated dedifferentiation of chondrocytes. Furthermore, culturing MSCs on microfluidic chips that mimic interstitial flow shear stress increases YAP and TAZ activity in an Rho-Rho-associated coiled-coil containing protein kinase (ROCK)-dependent manner, enhancing osteogenic and fibrochondrogenic differentiation $(8,22)$. Dupont et al (3) used rigid vs. highly elastic micropillars to assess the effects of cell-generated mechanical force; on the elastic substrate, cytoplasmic localization of YAP/TAZ was markedly increased. Collectively, it has been indicated that YAP/TAZ responds to cytoskeletal tension (3). Wang et al (23) used a parallel flow chamber to perform in vitro shear stress experiments and a partial carotid ligation model in apolipoprotein E-deficient mice to perform in vivo flow perturbation experiments. They proved that the activation and expression levels of YAP/TAZ were lower in the laminar flow region of the straight segment of thoracic aorta than in the disturbed flow region of the inner curvature of aortic arch (Fig. 1) (23).

ECM stiffness and shape. Each organ of the human body has a specific ECM stiffness. The role of mechanical cues needs to be understood in the context of the multicellular organization that characterizes natural tissue $(24,25)$. The importance of ECM sensing elasticity has been demonstrated in fibroblasts, mesenchymal and epidermal stem cells and other areas of cells $(5,26-28)$. For example, gelatinous polyacrylamide gel has been used as an artificial cell matrix for in vitro adherence culture of cells. The cell matrix was induced to take on a different stiffness by adjusting the proportion of chemical components and human epidermal stem cells were cultured in the matrix. The results showed that different levels of stiffness had different effects on the shape of cell growth $(5,29)$. When cells were cultured on a soft matrix, which is similar to brain tissue, they exhibited characteristics of neurons; when cells were cultured on a middle-stiffness matrix, which is similar to muscle tissue, they showed characteristics of myocytes; and when cells were cultured on a hard matrix, which is similar to collagen, they showed characteristics of osteoblastic differentiation (30). Thus, the varying elastic properties of the different tissue types seem to influence tissue regeneration.

Different basal shapes of cell culture have an important effect on cell proliferation and differentiation. In vitro cell culture experiments have demonstrated that cell proliferation is fastest in the outer region of the culture dish (31). In round dishes, this area is the outermost circle, while in square dishes the fastest proliferation occurs in the four corners. There is also research suggesting that the topological terrain of the substrate serves an important role in regulating the stemness of stem cells. Clones formed in a groove and column are relatively flat, whereas clones formed in a hexagonal pattern are more rounded $(25,32)$. Based on these reports, it is hypothesized that ECM shape induces cell geometry and regulates cell fate and behavior. In similar studies, microprinted ECM islands of different sizes were engineered to control the extent of spreading of a single endothelial cell $(28,33,34)$. It was observed that well-spread cells proliferated, whereas cells confined to small adhesive areas did not proliferate and instead underwent apoptosis. It has been proven that this effect was due to changes in cell shape, rather than due to the extent of cell-ECM contact (13).

It has been proposed that cell fate induced by stiff ECM requires YAP/TAZ function and, conversely, cell fate associated with soft ECM requires its inactivation (Fig. 1) (35-37). The activity of YAP/TAZ in cells grown on stiff hydrogels is comparable to that of cells grown on plastics, whereas growing cells on soft matrices inhibits YAP/TAZ activity to levels comparable with that of short interfering RNA-mediated YAP/TAZ depletion (3).

Internal force of cytoskeleton. The cytoskeleton, within the cytoplasm, is a fundamental structure for mediating force transmission $(38,39)$. It contains filamentous actin, intermediate filaments and microtubules that transmit force over long distances in the cell. Various types of external force applied to the cell can be transformed into internal force via the cytoskeleton. Therefore, force transmission contains both an external component and an internal component and is completed via the cytoskeleton (40). Focal adhesions, a type of multiprotein clustered from integrins, provide a direct physical link between the ECM and cytoskeletal adaptors, consequently connecting the ECM with the actin cytoskeleton (24). The organization of the cytoskeleton sustains cell shape; however, the dynamics of actin microfilaments are the focus of much research on mechanotransduction $(41,42)$.

Experiments using Drosophila have revealed that increased actin stress fiber assembly correlates with YAP nuclear localization and overgrowth of the wing disc $(43,44)$. However, it is unclear by which mechanisms cytoskeletal tension regulates YAP/TAZ, although the nucleus may serve a mechanotransductive role in the regulation of YAP (45). The focal adhesions and stress fibers that are generated on stiff substrates transduce mechanical forces to the nucleus, leading to nuclear flattening. This increases YAP nuclear import by decreasing mechanical restriction in nuclear pores $(46,47)$.

Cell geometry. A number of stem cells differentiate into distinct lineages depending on local cues present in their environment. Previous studies have suggested that changes in cell shape regulate the degree of development of lineage-specific markers, or differentiation, in pre-committed preadipocytes or preosteoblasts $(10,48)$. Different basal shapes of cell culture have an important effect on cell proliferation and differentiation. Average focal-adhesion stress per cell increases with micropost rigidity for both human MSCs and umbilical vein endothelial cells but to different magnitudes in each cell type $(49,50)$. These differences in focal adhesion stress 


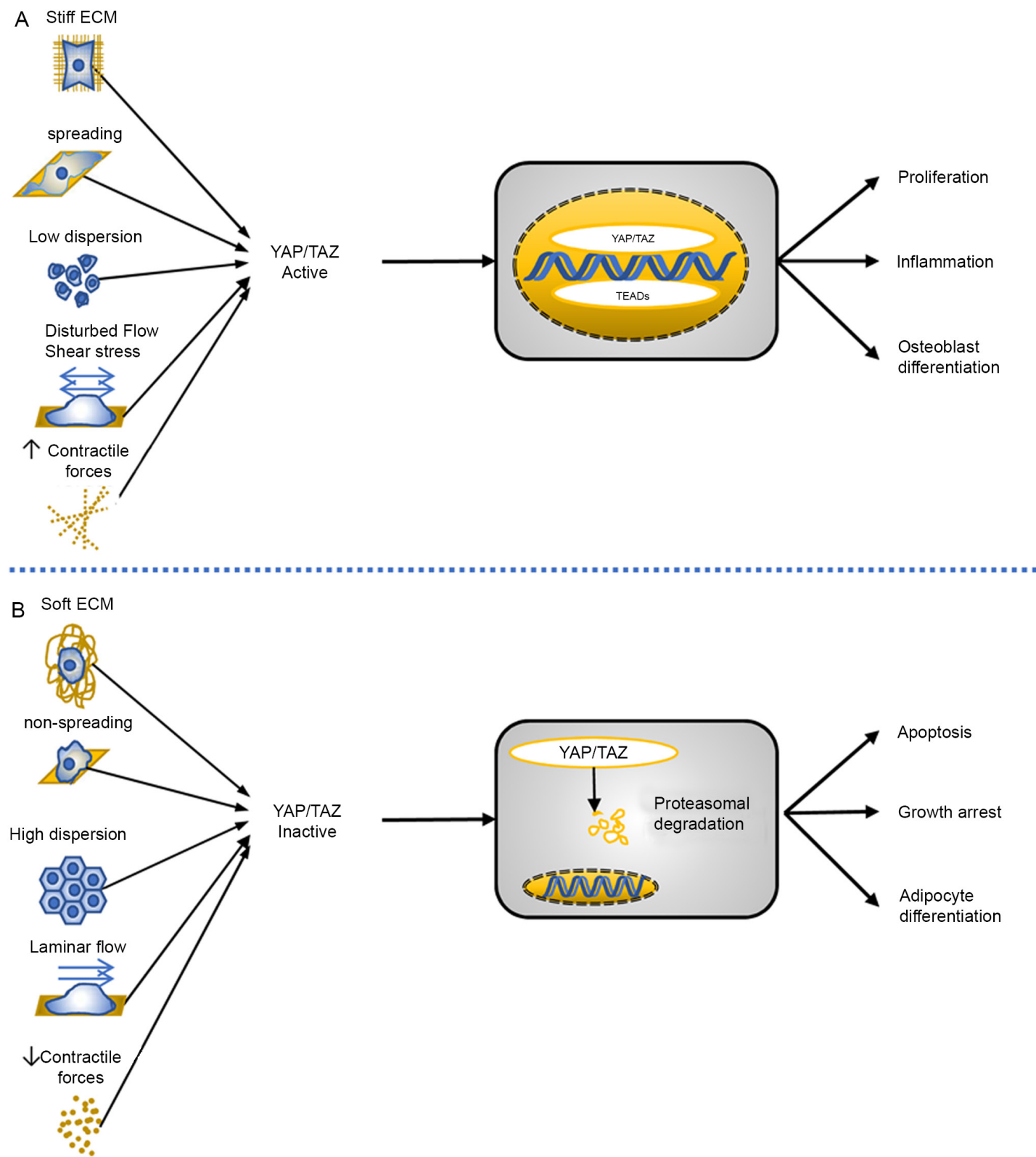

Figure 1. (A) Activation of YAP/TAZ by high levels of mechanical cues; (B) Inactivation of YAP/TAZ by low levels of mechanical cues. Different mechanical inputs regulate YAP activity. When YAP is active, it promotes cell proliferation and osteoblast differentiation and inflammation. When YAP is inactive, it improves proteasomal degradation and contributes to apoptosis and growth arrest and adipocyte differentiation. YAP, yes-associated protein; TAZ, transcriptional coactivator with PDZ-binding motif; ECM, extracellular matrix; TEAD, the transcriptional enhanced associate domain.

between cell types suggest that there may be multiple ways for cells to mechanically adapt to their environment (49).

Cells seeded on stiff hydrogels or large islands show increased cell spreading and greater cell-ECM contact. YAP/TAZ was localized in the nucleus when cells were seeded on micropillars, indicating that YAP/TAZ are primarily regulated by cell spreading imposed by the ECM $(51,52)$. Morphometric analysis of cell populations revealed a strong correlation between focal adhesions and cell spreading, regardless of micropost rigidity (49). These findings indicate how ECM is able to mediate its effects on stem cell morphology and stemness, and show the role of mechanotransduction and stiffness on cell fate determination $(53,54)$.

Changes in shape and morphological characteristics occur during and after cell differentiation. Previous studies have proven that there is an important connection between cell morphology and proliferation, survival and differentiation $(55,56)$. Cell shape may impact the state transition of cell from life to death or between proliferation and quiescence (57).

Fibronectin-coated micropillars have been used to test whether YAP/TAZ is regulated by cell spreading independently of the total amount of ECM $(3,49)$. It has been shown that the actual area available for cell-ECM interaction is only $\sim 10 \%$ of their projected area and YAP/TAZ remained nuclear on micropillars, indicating that YAP/TAZ is primarily regulated by cell spreading imposed by the ECM (Fig. 1) $(3,51)$. Similarly, Wada et al (58) proposed a model by using a microdomain culture system in which the cell area of a single cell was defined, while cell-cell contact was prevented to show that cell morphology alone can modulate YAP activity. 
The geometrical morphology and area of cell spread are associated with proliferation, differentiation and migration of bone marrow MSCs. When the width of the cells is narrow, the proliferation of bone marrow MSCs is inhibited and cell migration is enhanced when the cell area is limited (59-61).

\section{Mechanism of YAP/TAZ regulation}

A growing body of research has revealed that YAP/TAZ serves a central role in delivering information of mechanical environments surrounding cells to the nucleus transcriptional machinery via Hippo and non-Hippo mechanisms; this is an underlying principle for YAP/TAZ-mediated regulation of biological functions $(9,62,63)$. YAP also interacts with components of other signaling pathways, which serve a role in mechanotransduction (64-66). However, the focus of most research has been the mechanism by which mechanical signals regulate YAP/TAZ activity.

Classic Hippo signaling pathway and YAP/TAZ regulation. The Hippo pathway serves a key role in the regulation of tissue homeostasis, abnormalities of which are associated with human cancer. Research has provided an overview of the functional importance of numerous Hippo pathway components. It has been demonstrated that neurofibromin 2 and Ras Homolog Family Member A (RhoA) are important regulators of YAP/TAZ, and TAO kinase 1/3 are direct kinases for large tumor suppressor kinase (LATS) 1/2 (67). Phosphorylation activates LATS1/2, resulting in its activity as a kinase of YAP/TAZ (68). Hippo core components, as well as YAP and TAZ activity, are regulated by a variety of mechanisms (Fig. 2) (69-71). There is a requirement for balanced amounts of YAP/TAZ in neural stem and progenitor cells, which are involved in controlling the correct expansion of the progenitor pool and timely differentiation; this may be ensured by a crosstalk system between CDK5 regulatory subunit-associated protein 2 and the Hippo pathway (72). YAP/TAZ transfers into the nucleus and participates in proliferation with the transcriptional enhanced associate domain (TEADs) following dephosphorylation by phosphatases, including protein phosphatase 1A and 2A (73-75).

Mechanical signals act on the Rho protein to promote the effect of filamentous (F-)actin, which resists LATS1/2. LATS1/2 has a YAP/TAZ complex that inhibits phosphorylation of the Snail/Slug-YAP/TAZ complex in the nucleus and cytoplasm, while phosphorylated YAP/TAZ in the cytoplasm promotes the Snail-YAP/TAZ complex formation. Therefore, mechanical signaling controls the function of YAP/TAZ via the classic Hippo pathway (Fig. 2).

Ras-related protein 2 (RAP2) GTPase has been identified as a key intracellular mechanotransducer that relays extracellular mechanical signals for transcriptional regulation via the Hippo pathway (76). ECM stiffness acts via RAP2 and its downstream Hippo kinase cascade to modulate a YAP/TAZ-mediated mechanoresponsive transcriptome. The identification of this signaling axis provides mechanistic insights into how cellular machinery is driven by mechanical stimuli (Fig. 3). In addition, another study validated the role of AT-rich interaction domain (ARID)1A-containing SWitch/sucrose non-fermentable (SWI/SNF) complex as a

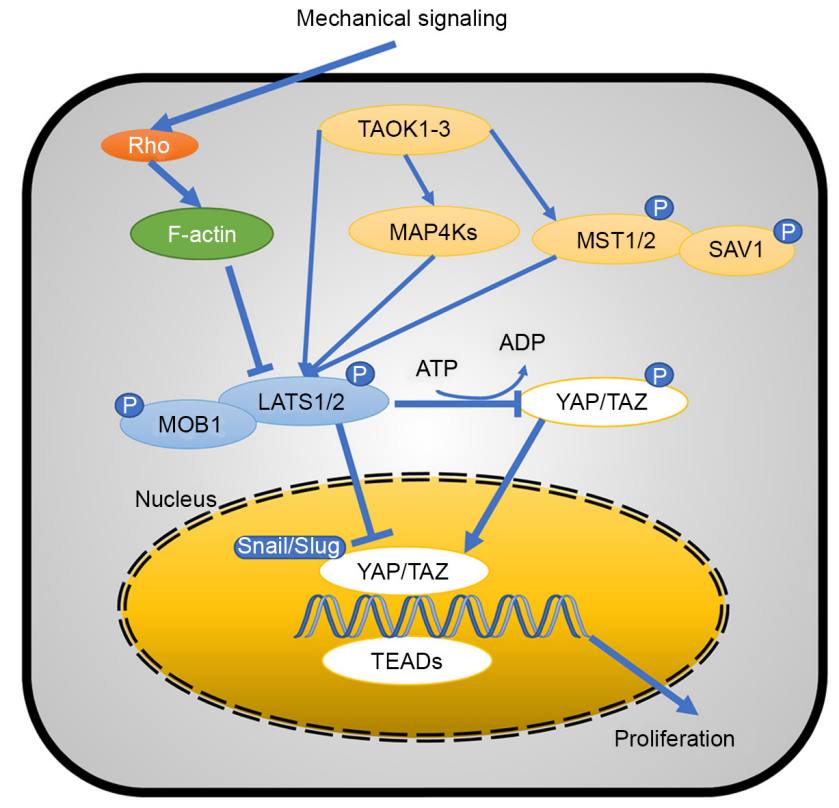

Figure 2. YAP/TAZ in Hippo pathway. The Hippo pathway serves an important role in the regulation of tissue homeostasis. Hippo core components, as well as YAP and TAZ activity, are regulated by a variety of mechanisms. YAP/TAZ transfers into the nucleus and participates in proliferation with TEADs following dephosphorylation. YAP/TAZ, yes-associated protein/transcriptional coactivator with PDZ-binding motif; TEAD, the transcriptional enhanced associate domain; F-actin, filamentous actin; TAOK, TAO kinase; SAV, Salvador family WW-domain-containing protein; LATS, large tumor suppressor kinase; MOB1, MOB kinase activator 1; P, phosphorylated; MST, macrophage stimulating.

mechanoregulated inhibitor of YAP/TAZ in vivo (77). In environments with high levels of mechanical stress, nuclear F-actin binds to ARID1A-SWI/SNF, thereby relieving YAP/TAZ from SWI/SNF inhibition in favor of an association between TEAD and YAP/TAZ.

ROCK signaling pathway. Tissue stiffness can be a predictor of tumor development and carries a high risk of pathogenesis of malignant transformation $(78,79)$; to the best of our knowledge, however, the association between tissue rigidity and tumor pathogenesis has not been fully characterized. The situation is similar for stem cell self-renewal and regulation of differentiation (1). Research has shown that tumor rigidity reflects an increase in stromal stiffness and tumor cell tension (26). Rho GTPase-dependent ROCK activation upregulates cytoskeletal tension by triggering the assembly of actomyosin networks (80). RhoA-mediated adipogenesis depends on a circular or expanded shape, whereas in of RhoA-mediated osteogenesis, RhoA effector ROCK constitutive activation induces osteogenesis independent of cell shape (10). This RhoA-ROCK commitment signal requires actin-myosin to produce tension. Studies have shown that the commitment of stem cells to various lineages is modulated by different physical cues embodied by cytoskeletal tension, cell shape and RhoA signaling (Fig. 4) (10,81,82).

It has been demonstrated that membrane type 1 (MT1)-MMP directs skeletal stem cell lineage commitment and differentiation by controlling ECM remodeling, in turn promoting cytoskeletal tension via the integrin-RhoA-ROCK 


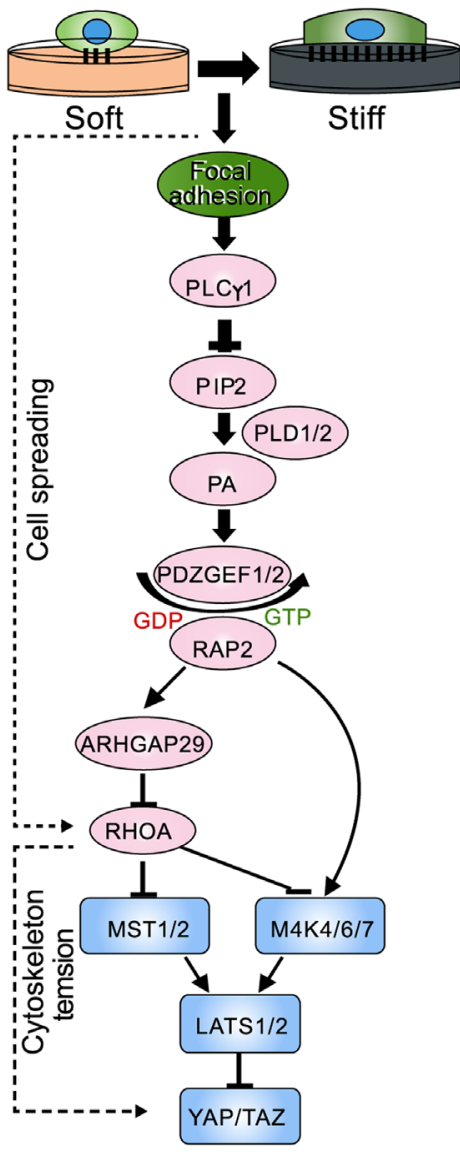

Figure 3. Signaling pathway by which stiffness regulates YAP/TAZ RAP2 is a key intracellular mechanotransducer that relays extracellular mechanical signals for transcriptional regulation through the Hippo pathway. Extracellular matrix stiffness acts via RAP2 and its downstream Hippo kinase cascade to modulate a YAP/TAZ-mediated mechanoresponsive transcriptome. YAP/TAZ, yes-associated protein/transcriptional coactivator with PDZ-binding motif; RAP2, Ras-related protein 2; PL, phospholipase; ARHGAP29, rho GTPase activating protein 29; LATS, large tumor suppressor kinase, PIP2, Phosphatidylinositol 4,5-bisphosphate; PA, phosphatidic acid; PDZGEF1/2, PDZ-guanine nucleotide exchange factor 1/2; MST1/2, macrophage stimulating 1/2; M4K4/6/7 (MAP4K4, MAP4K6, MAP4K7), Mitogen-activated protein kinase kinase kinase kinase 4/6/7.

pathway, thereby triggering nuclear localization of YAP/TAZ co-transcriptional activators, which activates a program that favors osteogenic differentiation over alternative adipogenic and chondrogenic cell fate (52).

TGF- $\beta$ signaling pathway. Both TGF- $\beta$ canonical and non-canonical signaling cascades simultaneously occur via crosstalk of core pathway components and combined utilization of SMAD/non-SMAD transcription factors (83). Tissue mechanics are translated into the activation or inhibition of transcription factors and their co-activating factors (84). Previous research has investigated the impact of morphological alterations on cellular signaling of TGF $\beta-1(85,86)$. From the non-canonical TGF- $\beta$ signaling pathway, Rho and ROCK activate F-actin and RhoA activates ROCK and mammalian diaphanous (mDia); ROCK activates MCC regulator of Wnt signaling pathway (MCC) and LIM domain kinase (LIMK) (87); LIMK activates Cofilin; and mDia, MCC and Cofilin activate F-actin (88). This is a cascade amplification process (Fig. 5). Canonical TGF $/$ /bone morphogenetic

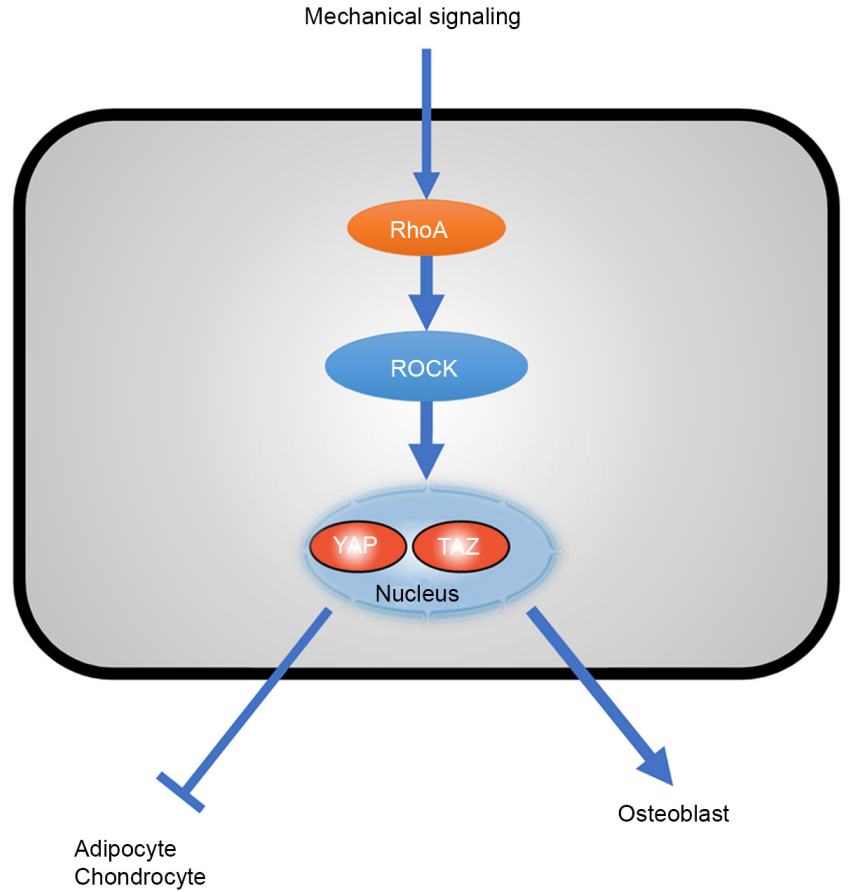

Figure 4. ROCK signaling pathway. Mechanical signaling acts via the integrin-RhoA-ROCK pathway, thereby triggering nuclear localization of the YAP/TAZ co-transcriptional activators, which activates a program that favors osteogenic differentiation over alternative adipogenic and chondrogenic cell fate. YAP/TAZ, yes-associated protein/transcriptional coactivator with PDZ-binding motif; ROCK, Rho-associated coiled-coil containing protein kinase; RhoA, Ras Homolog Family Member A.

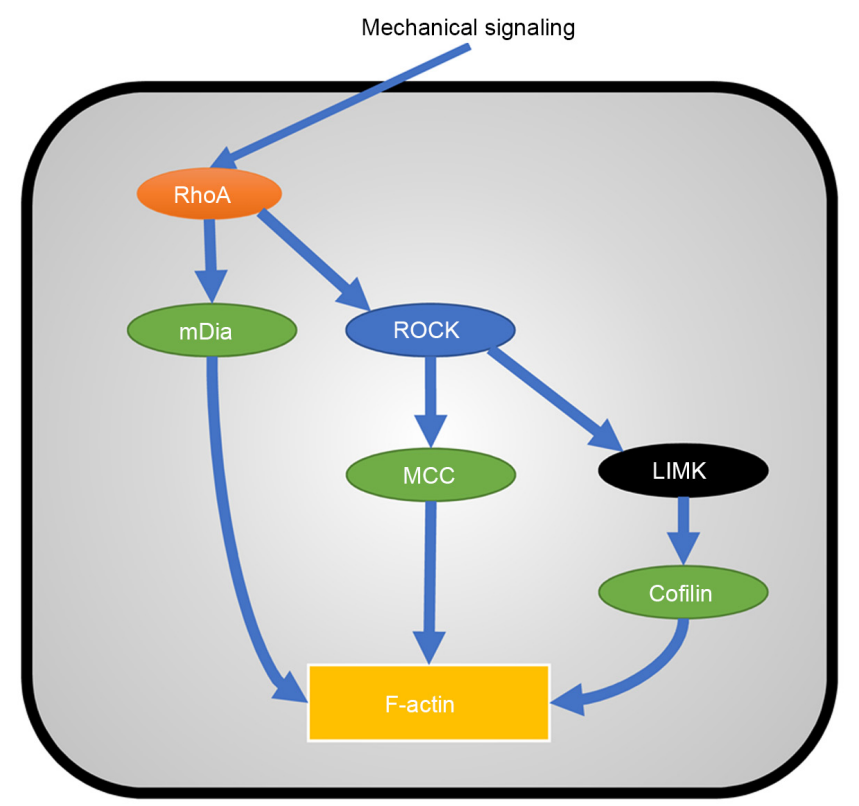

Figure 5. TGF- $\beta$ signaling pathway. YAP/TAZ are mechanoregulators of TGF- $\beta$-SMAD signaling. YAP/TAZ, yes-associated protein/transcriptional coactivator with PDZ-binding motif; ROCK, Rho-associated coiled-coil containing protein kinase; MCC, MCC regulator of Wnt signaling pathway; LIMK, LIM domain kinase; F-actin, filamentous actin; RhoA, Ras Homolog Family Member A; mDia, mammalian diaphanous.

protein (BMP) signaling acts via SMADs and has also been shown to be sensitive to mechanical inputs into the cell (89). It has been confirmed that YAP/TAZ are mechanoregulators 


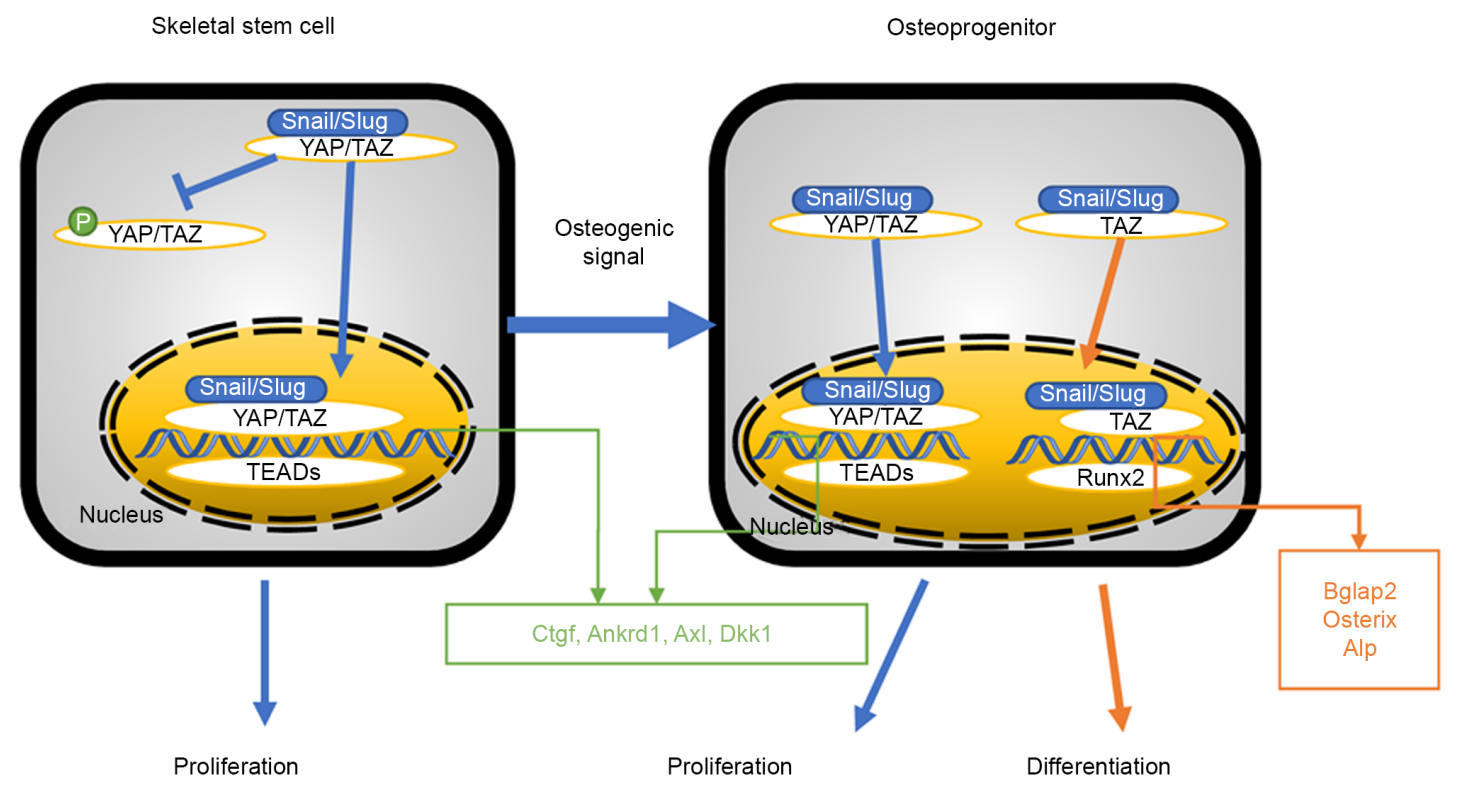

Figure 6. Snail/Slug binding interactions. The Snail/Slug-YAP/TAZ complex promotes YAP/TAZ phosphorylation in the cytoplasm and Snail/Slug-YAP/TAZ-TEAD complex in the nucleus, and induces expression of Ctgf, Ankrd1, Axl, Dkk1, and cell proliferation. YAP/TAZ, yes-associated protein/transcriptional coactivator with PDZ-binding motif; TEAD, the transcriptional enhanced associate domain; Ctgf, connective tissue growth factor; Ankrd1, ankyrin repeat domain 1; Ax1, axonin 1; Dkk1, Dickkopf-related protein 1; P, phosphorylated; Bglap2, bone $\gamma$-carboxyglutamate protein 2.

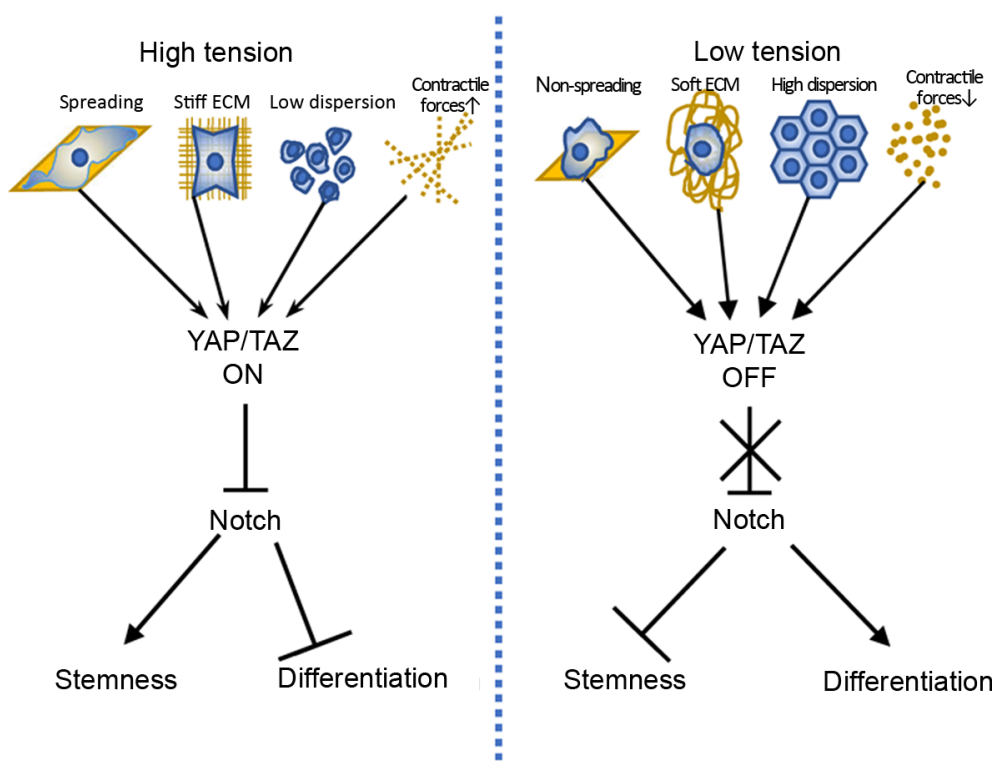

Figure 7. Notch signaling pathway. YAP/TAZ and notch regulation have a synergistic effect with each other to control stem cell preservation vs. differentiation and intercellular communication. YAP/TAZ, yes-associated protein/transcriptional coactivator with PDZ-binding motif.

of TGF- $\beta$-SMAD signaling (66). YAP/TAZ interaction with SMAD2/3 serves a key role in SMAD nuclear-cytoplasmic shuttling (90). YAP nuclear exclusion sequesters the SMAD2/3 protein to the cytoplasm and therefore suppresses TGF- $\beta$ signaling $(91,92)$. YAP binds to activated SMAD1 protein to enhance BMP-induced transcriptional activity (93). In addition, YAP/TAZ functions as an endogenous repressor of SMAD7 expression to modulate TGF- $\beta$ signaling (94).

Snail/Slug binding interactions. Bone-marrow-derived skeletal stem cell (SSC) self-renewal and function is key to bone development, in vivo balance and repair (95). Mechanically,
Snail/segment regulates SSC function by forming a complex with transcription co-activators YAP and TAZ and suppressing Hippo pathway-dependent adjustment of the YAP/TAZ signal cascade.In turn, the Snail/Slug-YAP/TAZ axis activates a series of YAP/TAZ-TEAD/Runx2 downstream targets that control the stability and osteogenesis of SSCs (65). In conclusion, these results indicate that SSCs mobilize the Snail/Slug-YAP/TAZ complex to control stem cell function (65).

The Snail/Slug-YAP/TAZ complex promotes YAP/TAZ phosphorylation in the cytoplasm and Snail/Slug-YAP/TAZ-TEADs complex in the nucleus, thus inducing expression of connective tissue growth factor, ankyrin 


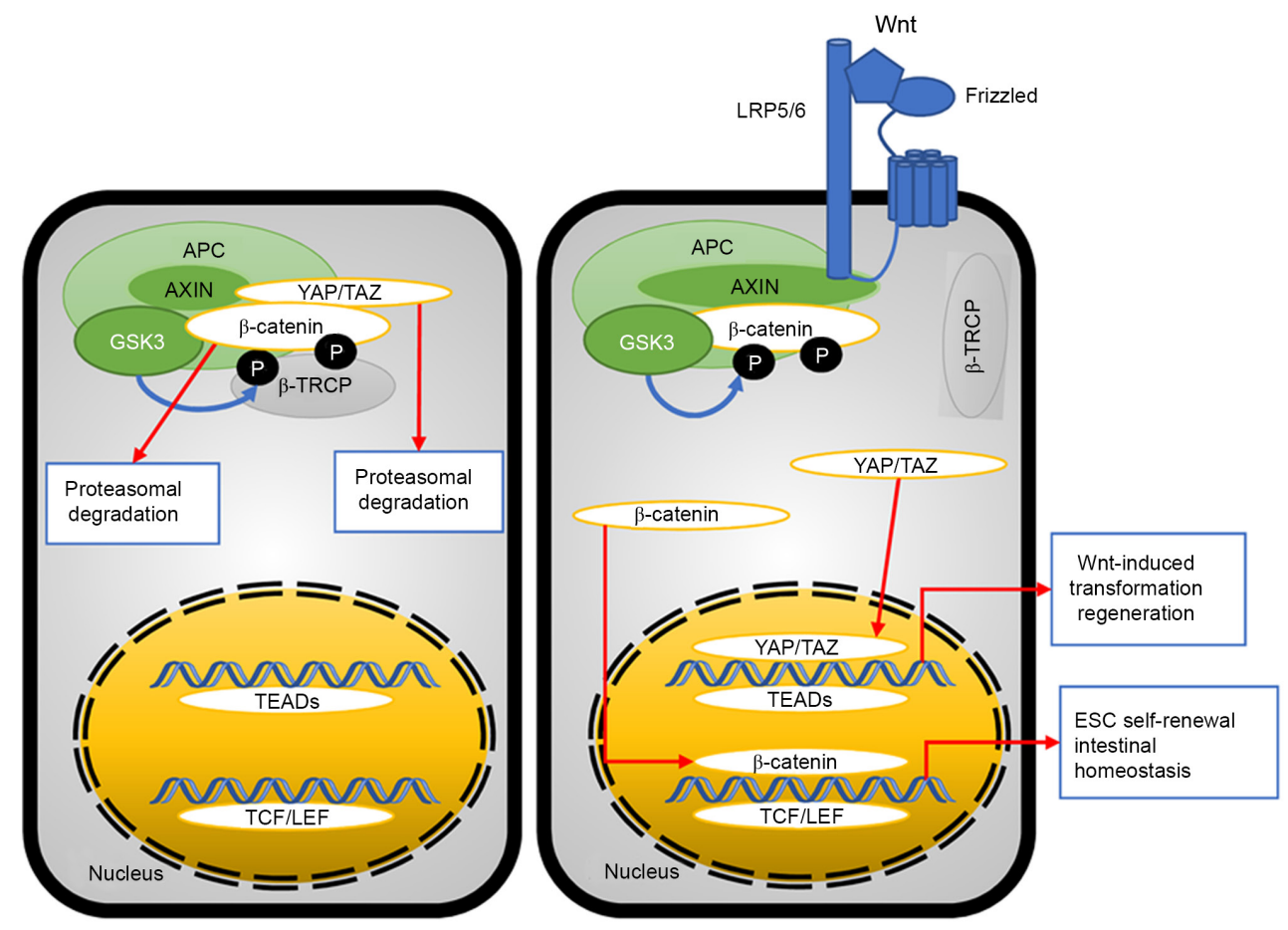

Figure 8. Wnt/ $\beta$-catenin pathway. The primary purpose of the YAP/TAZ-associated Wnt/ $\beta$ pathway is the control action of $\beta$-catenin. YAP/TAZ has to be banded with TEADs or $\beta$-catenin has to be banded with TCF/LEF in the nucleus to perform their roles. YAP/TAZ, yes-associated protein/transcriptional coactivator with PDZ-binding motif; TEAD, the transcriptional enhanced associate domain; TCF/LEF, transcription factor/lymphoid enhancer binding factor; P, phosphorylated; LRP, LDL receptor-related protein; ESC, embryonic stem cell; $\beta$-TRCP, $\beta$-transducin repeats-containing proteins; APC, adenomatous polyposis coli.

repeat domain 1, axonin 1 and Dickkopf-related protein 1, as well as cell proliferation (96). This is established in SSCs and osteoprogenitors. In osteoprogenitors, the Snail/Slug-TAZ complex promotes the Snail/Slug-TAZ-Runx2 complex in the nucleus (97), thereby inducing the expression of bone $\gamma$-carboxyglutamate protein 2, Osterix and Alp, and inducing differentiation (Fig. 6).

Hedgehog signaling pathway. Functional interactions between Hippo and the Sonic hedgehog (Shh) signaling pathway have been observed in medulloblastoma and neural differentiation $(98,99)$. Shh expression in the regenerating limb bud in Xenopus can be decreased under the functional inhibition of YAP (100). Furthermore, the Hedgehog pathway acts upstream of the Hippo pathway in regulating follicle stem cell maintenance in the Drosophila ovary, in which the Hedgehog pathway regulates Yorkie activity via a post-translational mechanism (101). It has been observed that in non-alcoholic steatohepatitis-associated liver injury and inflammation, injured hepatocytes release Shh ligands, which promotes the YAP-induced accumulation of reactive-appearing ductular cells (102). However, in healthy liver, the activation of YAP does not result in its growth (103). YAP/TAZ inhibition of smooth muscle cell differentiation is mediated by the Hedgehog pathway, but signal transduction in mouse embryonic pluripotent mesenchymal cells is not $(104,105)$. This suggests a working interaction between YAP and Shh signal transduction.

Notch signaling pathway. It has been reported that following loss of cell attachment to the basement membrane, epidermis

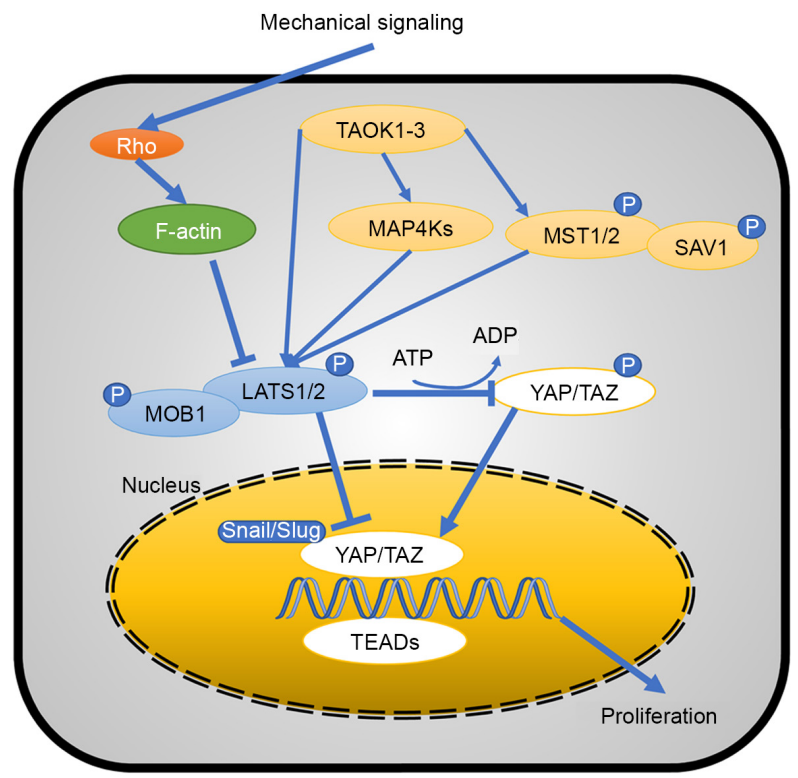

Figure 9. YAP and TAZ mechanotransduction in stem cell biology. A variety of mechanisms of YAP/TAZ regulation via the Hippo pathway and cross-talk with other signaling pathways have been identified. YAP/TAZ, yes-associated protein/transcriptional coactivator with PDZ-binding motif; F-actin, filamentous actin; TAOK, TAO kinase; SAV, Salvador family WW-domain-containing protein; LATS, large tumor suppressor kinase; MOB, MOB kinase activator; TEAD, the transcriptional enhanced associate domain; MAP4K4, Mitogen-activated protein kinase kinase kinase kinase 4; MST1/2, macrophage stimulating $1 / 2$.

cells begin a terminal differentiation program until they fall off from the tissue form surface (106-109). As YAP/TAZ 
serves an important role in organ size control during the period of embryonic development $(44,110-114)$ and the notch signaling pathway is core in the paradigm of the epidermis, it is hypothesized that YAP/TAZ and notch regulation have a synergistic effect with each other to control stem cell preservation vs. differentiation and intercellular communication (Fig. 7) (109). This was also confirmed by Totaro et al (109), who demonstrated that notch was downstream of YAP/TAZ and that inhibition of YAP/TAZ preserved the undifferentiated state of human epidermal stem cells, although the specific mechanism remains unclear.

Wnt/ $\beta$-catenin pathway. YAP/TAZ participates in the $\mathrm{Wnt} / \beta$-catenin pathway, which is involved in cell proliferation, tumorigenesis, regeneration and stem cell expansion (115-117). It has been confirmed that the primary purpose of the YAP/TAZ-associated Wnt/ $\beta$ pathway is control of $\beta$-catenin $(118,119)$. In cells lacking the Wnt signal, YAP and TAZ are sequestered in the $\beta$-catenin destruction complex and they play an essential role for phospho- $\beta$-catenin degradation by recruiting $\beta$-transducin repeats-containing proteins $(\beta$-TRCP) (118). As a result, there is no reason that YAP/TAZ has to be banded with TEADs or $\beta$-catenin has to be banded with TCF/LEF in the nucleus to perform their respective roles. (Fig. 8). In cells possessing the Wnt signal, $\beta$-TRCP is released, as well as $\beta$-catenin and YAP/TAZ; YAP/TAZ and $\beta$-catenin can transfer into the nucleus to form YAP/TAZ-TEAD and $\beta$-catenin-TCF/LEF complexes, resulting in Wnt-induced transformation regeneration and ESC self-renewal $(117,120)$. In addition, YAP/TAZ is the key downstream effector of alternative Wnt signaling to induce cell migration and osteogenic differentiation, as well as negative regulation of canonical Wnt/ $\beta$-catenin signaling (119). The functional interactions between Wnt activation and YAP localization have also been demonstrated in maintaining undifferentiated mouse ESCs $(64,121)$. Cytoplasmic YAP/TAZ can sequester $\beta$-catenin, resulting in the loss of self-renewal ability and differentiation activation of ESCs (121).

JNK pathway. The JNK pathway, one of the major signaling cassettes of the MAPK signaling pathway, serves an important role in cytoskeletal modulation, apoptosis and cell proliferation (122-124). JNK is a stress-activated kinase, which can be activated by stretch-induced actin stress $(123,125)$. LATS activity can be decreased by cyclic stretch stress due to increased LIM domain-containing 1-LATS1 banding through activation of JNK, consequently, leading to elevated YAP activity (126). In addition, YAP/TAZ activation induced by disturbed flow shear stress can promote inflammation and atherogenesis by enhancing JNK activity (127).

\section{Conclusion}

A variety of mechanisms controlling YAP/TAZ regulation have been described (Fig. 9). With research on structural and functional regulation of stem cells, the mechanical transduction mechanisms of response to stress have gained recognition, but there are still several unknown details. For example, YAP/TAZ has been identified in the mechanical mechanics micro-environment response $(3,62)$, but the specific details of the mechanism have yet to be studied. Therefore, further study of YAP/TAZ regulation is required to increase understanding of the role of force in the pathogenesis of certain diseases and the role of trauma repair processes in mediating these mechanisms, which may lead to novel effective treatment strategies $(128,129)$. This also applies to tissue engineering, gene therapy, stem cell regeneration medicine and space and aerospace medicine research.

Future research will investigate the mechanisms by which YAP/TAZ modulates cell mechanics to enable cell function and the role of YAP/TAZ in ECM shape-induced stem cell function and shape/geometry.

\section{Acknowledgements}

Not applicable.

\section{Funding}

The present review was supported by the National Natural Science Foundation of China (grant no. 81601619) and Science Research Foundation of Education Department of Liaoning (grant no. LZ2019008).

\section{Availability of data and materials}

Not applicable.

\section{Authors' contributions}

YL and WZ contributed to the conception of the review, wrote the manuscript, performed the literature search and prepared the original draft. JW performed the literature search and constructed the figures. All the authors read and approved the final manuscript. Data sharing is not applicable.

\section{Ethics approval and consent to participate}

Not applicable.

\section{Patient consent for publication}

Not applicable.

\section{Competing interests}

The authors declare that they have no competing interests.

\section{References}

1. Vining KH and Mooney DJ: Mechanical forces direct stem cell behaviour in development and regeneration. Nat Rev Mol Cell Biol 18: 728-742, 2017.

2. Demehri S and Kopan R: Notch signaling in bulge stem cells is not required for selection of hair follicle fate. Development 136: 891-896, 2009.

3. Dupont S, Morsut L, Aragona M, Enzo E, Giulitti S, Cordenonsi M, Zanconato F, Le Digabel J, Forcato M, Bicciato S, et al: Role of YAP/TAZ in mechanotransduction. Nature 474: 179-183, 2011.

4. Lee JH, Park HK and Kim KS: Intrinsic and extrinsic mechanical properties related to the differentiation of mesenchymal stem cells. Biochem Biophys Res Commun 473: 752-757, 2016. 
5. Engler AJ, Sen S, Sweeney HL and Discher DE: Matrix elasticity directs stem cell lineage specification. Cell 126: 677-689, 2006.

6. Li D, Zhou J, Chowdhury F, Cheng J, Wang N and Wang F: Role of mechanical factors in fate decisions of stem cells. Regen Med 6: 229-240, 2011.

7. Oh S, Brammer KS, Li YS, Teng D, Engler AJ, Chien S and Jin S: Stem cell fate dictated solely by altered nanotube dimension. Proc Natl Acad Sci USA 106: 2130-2135, 2009.

8. Zhong W, Tian K, Zheng X, Li L, Zhang W, Wang S and Qin J: Mesenchymal stem cell and chondrocyte fates in a multishear microdevice are regulated by Yes-associated protein. Stem Cells Deve 22: 2083-2093, 2013.

9. Ishihara $\mathrm{E}$ and Nishina H: Role of Hippo-YAP/TAZ signaling pathway in mechanotransduction. Clin Calcium 26: 1751-1756, 2016 (In Japanese).

10. McBeath R, Pirone DM, Nelson CM, Bhadriraju K and Chen CS: Cell shape, cytoskeletal tension, and RhoA regulate stem cell lineage commitment. Dev Cell 6: 483-495, 2004.

11. Dupont S: Role of YAP/TAZ in cell-matrix adhesion-mediated signalling and mechanotransduction. Exp Cell Res 343: 42-53, 2016.

12. Pocaterra A, Romani P and Dupont S: YAP/TAZ functions and their regulation at a glance. J Cell Sci 133: jcs230425, 2020.

13. Pan JX, Xiong L, Zhao K, Zeng P, Wang B, Tang FL, Sun D, Guo HH, Yang X, Cui S, et al: YAP promotes osteogenesis and suppresses adipogenic differentiation by regulating $\beta$-catenin signaling. Bone Res 6: 18, 2018.

14. Oliver-De La Cruz J, Nardone G, Vrbsky J, Pompeiano A, Perestrelo AR, Capradossi F, Melajová K, Filipensky P and Forte G: Substrate mechanics controls adipogenesis through YAP phosphorylation by dictating cell spreading. Biomaterials 205: 64-80, 2019.

15. Yang Y, Wang BK, Chang ML, Wan ZQ and Han GL: Cyclic stretch enhances osteogenic differentiation of human periodontal ligament cells via YAP activation. BioMed Res Int 2018: 2174824 2018.

16. Kim NG, Koh E, Chen X and Gumbiner BM: E-cadherin mediates contact inhibition of proliferation through Hippo signaling-pathway components. Proc Natl Acad Sci USA 108: 11930-11935, 2011.

17. Xue X, Hong X, Li Z, Deng CX and Fu J: Acoustic tweezing cytometry enhances osteogenesis of human mesenchymal stem cells through cytoskeletal contractility and YAP activation. Biomaterials 134: 22-30, 2017

18. Hu JK, Du W, Shelton SJ, Oldham MC, DiPersio CM and Klein OD: An FAK-YAP-mTOR signaling axis regulates stem cell-based tissue renewal in mice. Cell Stem Cell 21: 91-106.e6, 2017.

19. Lecarpentier E, Bhatt M, Bertin GI, Deloison B, Salomon LJ Deloron P, Fournier T, Barakat AI and Tsatsaris V: Computational fluid dynamic simulations of maternal circulation: Wall shear stress in the human placenta and its biological implications PLoS One 11: e0147262, 2016.

20. Adamo L and Garcia-Cardeña G: Directed stem cell differentiation by fluid mechanical forces. Antioxid Redox Signal 15: $1463-1473,2011$

21. Kaneko K, Ito M, Naoe Y, Lacy-Hulbert A and Ikeda K: Integrin alphav in the mechanical response of osteoblast lineage cells. Biochem Biophys Res Commun 447: 352-357, 2014.

22. Zhong W, Zhang W, Wang S and Qin J: Regulation of fibrochondrogenesis of mesenchymal stem cells in an integrated microfluidic platform embedded with biomimetic nanofibrous scaffolds. PLoS One 8: e61283, 2013.

23. Wang KC, Yeh YT, Nguyen P, Limqueco E, Lopez J, Thorossian S, Guan KL, Li YJ and Chien S: Flow-dependent YAP/TAZ activities regulate endothelial phenotypes and atherosclerosis. Proc Natl Acad Sci USA 113: 11525-11530, 2016.

24. Halder G, Dupont S and Piccolo S: Transduction of mechanical and cytoskeletal cues by YAP and TAZ. Nat Rev Mol Cell Biol 13: 591-600, 2012

25. Wang Y, Wang G, Luo X, Qiu J and Tang C: Substrate stiffness regulates the proliferation, migration, and differentiation of epidermal cells. Burns 38: 414-420, 2012

26. Paszek MJ, Zahir N, Johnson KR, Lakins JN, Rozenberg GI, Gefen A, Reinhart-King CA, Margulies SS, Dembo M, Boettiger $\mathrm{D}$, et al: Tensional homeostasis and the malignant phenotype. Cancer Cell 8: 241-254, 2005.

27. Discher DE, Janmey P and Wang YL: Tissue cells feel and respond to the stiffness of their substrate. Science 310: 1139-1143, 2005.
28. Connelly JT, Gautrot JE, Trappmann B, Tan DW, Donati G, Huck WT and Watt FM: Actin and serum response factor transduce physical cues from the microenvironment to regulate epidermal stem cell fate decisions. Nat Cell Biol 12: 711-718, 2010.

29. Li Z, Gong Y, Sun S, Du Y, Lü D, Liu X and Long M: Differential regulation of stiffness, topography, and dimension of substrates in rat mesenchymal stem cells. Biomaterials 34: 7616-7625, 2013.

30. Hadden WJ, Young JL, Holle AW, McFetridge ML, Kim DY, Wijesinghe P, Taylor-Weiner H, Wen JH, Lee AR, Bieback K, et al: Stem cell migration and mechanotransduction on linear stiffness gradient hydrogels. Proc Natl Acad Sci USA 114: 5647-5652, 2017.

31. Nelson CM and Bissell MJ: Modeling dynamic reciprocity: Engineering three-dimensional culture models of breast architecture, function, and neoplastic transformation. Semin Cancer Biol 15: 342-352, 2005.

32. Witkowska-Zimny M, Walenko K, Wrobel E, Mrowka P, Mikulska A and Przybylski J: Effect of substrate stiffness on the osteogenic differentiation of bone marrow stem cells and bone-derived cells. Cell Biol Int 37: 608-616, 2013.

33. Brusatin G, Panciera T, Gandin A, Citron A and Piccolo S: Biomaterials and engineered microenvironments to control YAP/TAZ-dependent cell behaviour. Nat Mater 17: 1063-1075, 2018.

34. Singhvi R, Kumar A, Lopez GP, Stephanopoulos GN, Wang DI, Whitesides GM and Ingber DE: Engineering cell shape and function. Science 264: 696-698, 1994

35. Kuroda M, Wada H, Kimura Y, Ueda K and Kioka N: Vinculin promotes nuclear localization of TAZ to inhibit ECM stiffness-dependent differentiation into adipocytes. J Cell Sci 130: 989-1002, 2017.

36. Musah S, Morin SA, Wrighton PJ, Zwick DB, Jin S and Kiessling LL: Glycosaminoglycan-binding hydrogels enable mechanical control of human pluripotent stem cell self-renewal. ACS Nano 6: 10168-10177, 2012.

37. Caliari SR, Vega SL, Kwon M, Soulas EM and Burdick JA: Dimensionality and spreading influence MSC YAP/TAZ signaling in hydrogel environments. Biomaterials 103: 314-323, 2016.

38. Wang N, Butler JP and Ingber DE: Mechanotransduction across the cell surface and through the cytoskeleton. Science 260: 1124-1127, 1993

39. Eyckmans J, Boudou T, Yu X and Chen CS: A hitchhiker's guide to mechanobiology. Deve Cell 21: 35-47, 2011.

40. Dogterom M, Kerssemakers JW, Romet-Lemonne G and Janson ME: Force generation by dynamic microtubules. Curr Opin Cell Biol 17: 67-74, 2005.

41. Vogel V and Sheetz M: Local force and geometry sensing regulate cell functions. Nat Rev Mol Cell Biol 7: 265-275, 2006.

42. Schwartz MA: Integrins and extracellular matrix in mechanotransduction. Cold Spring Harb Perspect Biol 2: a005066, 2010.

43. Fernandez BG, Gaspar P, Bras-Pereira C, Jezowska B, Rebelo SR and Janody F: Actin-Capping Protein and the Hippo pathway regulate F-actin and tissue growth in Drosophila. Development 138: 2337-2346, 2011.

44. Sansores-Garcia L, Bossuyt W, Wada K, Yonemura S, Tao C, Sasaki $\mathrm{H}$ and Halder G: Modulating F-actin organization induces organ growth by affecting the Hippo pathway. EMBO J 30: 2325-2335, 2011

45. Chakraborty S, Njah K, Pobbati AV, Lim YB, Raju A, Lakshmanan M, Tergaonkar V, Lim CT and Hong W: Agrin as a Mechanotransduction signal regulating YAP through the hippo pathway. Cell Rep 18: 2464-2479, 2017.

46. Elosegui-Artola A, Andreu I, Beedle AEM, Lezamiz A, Uroz M, Kosmalska AJ, Oria R, Kechagia JZ, Rico-Lastres P, Le Roux AL, et al: Force triggers YAP nuclear entry by regulating transport across nuclear pores. Cell 171: 1397-1410.e14, 2017.

47. Dasgupta I and McCollum D: Control of cellular responses to mechanical cues through YAP/TAZ regulation. J Biol Chem 294: 17693-17706, 2019

48. Cawthorn WP, Scheller EL and MacDougald OA: Adipose tissue stem cells meet preadipocyte commitment: Going back to the future. J Lipid Res 53: 227-246, 2012.

49. Fu J, Wang YK, Yang MT, Desai RA, Yu X, Liu Z and Chen CS: Mechanical regulation of cell function with geometrically modulated elastomeric substrates. Nat Methods 7: 733-736, 2010.

50. Geng Y and Wang Z: Review of cellular mechanotransduction on micropost substrates. Med Biol Eng Comput 54: 249-271, 2016. 
51. Sero JE and Bakal C: Multiparametric analysis of cell shape demonstrates that beta-PIX directly couples YAP activation to extracellular matrix adhesion. Cell Syst 4: 84-96.e86, 2017.

52. Tang Y, Rowe RG, Botvinick EL, Kurup A, Putnam AJ, Seiki M, Weaver VM, Keller ET, Goldstein S, Dai J, et al: MT1-MMP-dependent control of skeletal stem cell commitment via a $\beta 1$-integrin/YAP/TAZ signaling axis. Dev Cell 25: 402-416, 2013.

53. Gattazzo F, Urciuolo A and Bonaldo P: Extracellular matrix: A dynamic microenvironment for stem cell niche. Biochim Biophys Acta 1840: 2506-2519, 2014.

54. Lu D, Luo C, Zhang C, Li Z and Long M: Differential regulation of morphology and stemness of mouse embryonic stem cells by substrate stiffness and topography. Biomaterials 35: 3945-3955, 2014.

55. Pucci B, Kasten M and Giordano A: Cell cycle and apoptosis. Neoplasia 2: 291-299, 2000.

56. Pittenger MF, Discher DE, Peault BM, Phinney DG, Hare JM and Caplan AI: Mesenchymal stem cell perspective: Cell biology to clinical progress. NPJ Regen Med 4: 22, 2019.

57. Chen CS, Mrksich M, Huang S, Whitesides GM and Ingber DE: Geometric control of cell life and death. Science 276: 1425-1428, 1997.

58. Wada K, Itoga K, Okano T, Yonemura S and Sasaki H: Hippo pathway regulation by cell morphology and stress fibers. Development 138: 3907-3914, 2011.

59. Pek YS, Wan AC and Ying JY: The effect of matrix stiffness on mesenchymal stem cell differentiation in a 3D thixotropic gel. Biomaterials 31: 385-391, 2010.

60. Burke DP and Kelly DJ: Substrate stiffness and oxygen as regulators of stem cell differentiation during skeletal tissue regeneration: A mechanobiological model. PLoS One 7: e40737, 2012.

61. Tse JR and Engler AJ: Stiffness gradients mimicking in vivo tissue variation regulate mesenchymal stem cell fate. PLoS One 6: e15978, 2011.

62. Panciera T, Azzolin L, Cordenonsi $\mathrm{M}$ and Piccolo $\mathrm{S}$ : Mechanobiology of YAP and TAZ in physiology and disease. Nat Rev Mol Cell Biol 18: 758-770, 2017.

63. Hansen CG, Moroishi T and Guan KL: YAP and TAZ: A nexus for Hippo signaling and beyond. Trends Cell Biol 25: 499-513, 2015.

64. Bejoy J, Song L and Li Y: Wnt-YAP interactions in the neural fate of human pluripotent stem cells and the implications for neural organoid formation. Organogenesis 12: 1-15, 2016.

65. Tang Y, Feinberg T, Keller ET, Li XY and Weiss SJ: Snail/Slug binding interactions with YAP/TAZ control skeletal stem cell self-renewal and differentiation. Nat Cell Biol 18: 917-929, 2016.

66. Szeto SG, Narimatsu M, Lu M, He X, Sidiqi AM, Tolosa MF Chan L, De Freitas K, Bialik JF, Majumder S, et al: YAP/TAZ Are mechanoregulators of TGF- $\beta$-Smad signaling and renal fibrogenesis. J Am Soc Nephrol 27: 3117-3128, 2016.

67. Plouffe SW, Meng Z, Lin KC, Lin B, Hong AW, Chun JV and Guan KL: Characterization of hippo pathway components by gene inactivation. Mol Cell 64: 993-1008, 2016.

68. Zhao B, Wei X, Li W, Udan RS, Yang Q, Kim J, Xie J, Ikenoue T, Yu J, Li L, et al: Inactivation of YAP oncoprotein by the Hippo pathway is involved in cell contact inhibition and tissue growth control. Genes Dev 21: 2747-2761, 2007.

69. Bae JS, Kim SM and Lee H: The Hippo signaling pathway provides novel anti-cancer drug targets. Oncotarget 8 16084-16098, 2016

70. Wang C, Gu C, Jeong KJ, Zhang D, Guo W, Lu Y, Ju Z Panupinthu N, Yang JY, Gagea MM, et al: YAP/TAZ-mediated upregulation of GAB2 leads to increased sensitivity to growth factor-induced activation of the PI3K pathway. Cancer Res 77: $1637-1648,2017$

71. Wang L, Luo JY, Li B, Tian XY, Chen LJ, Huang Y, Liu J, Deng D, Lau CW, Wan S, et al: Integrin-YAP/TAZ-JNK cascade mediates atheroprotective effect of unidirectional shear flow. Nature 540: 579-582, 2016

72. Sukumaran SK, Stumpf M, Salamon S, Ahmad I, Bhattacharya K, Fischer S, Müller R, Altmüller J, Budde B, Thiele $\mathrm{H}$, et al: CDK5RAP2 interaction with components of the Hippo signaling pathway may play a role in primary microcephaly. Mol Genet Genomics 292: 365-383, 2016.

73. Schlegelmilch K, Mohseni M, Kirak O, Pruszak J, Rodriguez JR, Zhou D, Kreger BT, Vasioukhin V, Avruch J, Brummelkamp TR and Camargo FD: Yap1 acts downstream of $\alpha$-catenin to control epidermal proliferation. Cell 144: 782-795, 2011.
74. Wang P, Bai Y, Song B, Wang Y, Liu D, Lai Y, Bi X and Yuan Z PP1A-mediated dephosphorylation positively regulates YAP2 activity. PLoS One 6: e24288, 2011.

75. Denis D, Rouleau C and Schaffhausen BS: A transformation-defective polyomavirus middle $\mathrm{T}$ antigen with a novel defect in PI3 kinase signaling. J Virol 91: e01774-16, 2017.

76. Meng Z, Qiu Y, Lin KC, Kumar A, Placone JK, Fang C, Wang KC, Lu S, Pan M, Hong AW, et al: RAP2 mediates mechanoresponses of the Hippo pathway. Nature 560: 655-660, 2018.

77. Chang L, Azzolin L, Di Biagio D, Zanconato F, Battilana G, Lucon Xiccato R, Aragona M, Giulitti S, Panciera T, Gandin A, et al: The SWI/SNF complex is a mechanoregulated inhibitor of YAP and TAZ. Nature 563: 265-269, 2018

78. Singh A, Brito I and Lammerding J: Beyond tissue stiffness and bioadhesivity: Advanced biomaterials to model tumor microenvironments and drug resistance. Trends Cancer 4: 281-291, 2018.

79. Lopez JI, Mouw JK and Weaver VM: Biomechanical regulation of cell orientation and fate. Oncogene 27: 6981-6993, 2008

80. Hoon JL, Tan MH and Koh CG: The regulation of cellular responses to mechanical cues by Rho GTPases. Cells 5: 17, 2016

81. Spector AA and Grayson WL: Stem cell fate decision making: Modeling approaches. ACS Biomater Sci Eng 3: 2702-2711, 2017.

82. Wu RX, Yin Y, He XT, Li X and Chen FM: Engineering a cell home for stem cell homing and accommodation. Adv Biosyst 1 : e1700004, 2017.

83. Costanza B, Umelo IA, Bellier J, Castronovo V and Turtoi A: Stromal modulators of TGF- $\beta$ in cancer. J Clin Med 6: 7, 2017.

84. Janmey PA, Wells RG, Assoian RK and McCulloch CA: From tissue mechanics to transcription factors. Differentiation 86 112-120, 2013

85. Muehlich S, Rehm M, Ebenau A and Goppelt-Struebe M: Synergistic induction of CTGF by cytochalasin D and TGFbeta-1 in primary human renal epithelial cells: Role of transcriptional regulators MKL1, YAP/TAZ and Smad2/3. Cell Signal 29: 31-40, 2017

86. Rana MK, Aloisio FM, Choi C and Barber DL: Formin-dependent TGF- $\beta$ signaling for epithelial to mesenchymal transition. Mol Biol Cell 29: 1465-1475, 2018.

87. Ng LF, Kaur P, Bunnag N, Suresh J, Sung ICH, Tan QH, Gruber J and Tolwinski NS: WNT signaling in disease. Cells 8: $826,2019$.

88. Mezzacappa C, Komiya Y and Habas R: Activation and function of small GTPases Rho, Rac, and Cdc42 during gastrulation. Methods Mol Biol 839: 119-131, 2012.

89. Maeda T, Sakabe T, Sunaga A, Sakai K, Rivera AL, Keene DR, Sasaki T, Stavnezer E, Iannotti J, Schweitzer R, et al: Conversion of mechanical force into TGF- $\beta$-mediated biochemical signals. Curr Biol 21: 933-941, 2011.

90. Varelas X, Sakuma R, Samavarchi-Tehrani P, Peerani R, Rao BM, Dembowy J, Yaffe MB, Zandstra PW and Wrana JL: TAZ controls Smad nucleocytoplasmic shuttling and regulates human embryonic stem-cell self-renewal. Nat Cell Biol 10 $837-848,2008$

91. Varelas X, Samavarchi-Tehrani P, Narimatsu M, Weiss A, Cockburn K, Larsen BG, Rossant J and Wrana JL: The Crumbs complex couples cell density sensing to Hippo-dependent control of the TGF- $\beta$-SMAD pathway. Dev Cell 19: 831-844, 2010.

92. Narimatsu M, Samavarchi-Tehrani P, Varelas X and Wrana JL: Distinct polarity cues direct Taz/Yap and TGF $\beta$ receptor localization to differentially control TGF $\beta$-induced Smad signaling. Dev Cell 32: 652-656, 2015

93. Alarcon C, Zaromytidou AI, Xi Q, Gao S, Yu J, Fujisawa S, Barlas A, Miller AN, Manova-Todorova K, Macias MJ, et al: Nuclear CDKs drive Smad transcriptional activation and turnover in BMP and TGF-beta pathways. Cell 139: 757-769, 2009

94. Qin Z, Xia W, Fisher GJ, Voorhees JJ and Quan T: YAP/TAZ regulates TGF- $\beta / \mathrm{Smad} 3$ signaling by induction of Smad7 via $\mathrm{AP}-1$ in human skin dermal fibroblasts. Cell Commun Signal 16: $18,2018$.

95. Serowoky MA, Arata CE, Crump JG and Mariani FV: Skeletal stem cells: Insights into maintaining and regenerating the skeleton. Development 147: dev179325, 2020

96. Tang Y and Weiss SJ: Snail/Slug-YAP/TAZ complexes cooperatively regulate mesenchymal stem cell function and bone formation. Cell Cycle 16: 399-405, 2017.

97. Kovar H, Bierbaumer L and Radic-Sarikas B: The YAP/TAZ pathway in osteogenesis and bone sarcoma pathogenesis. Cells 9: $972,2020$. 
98. Fernandez LA, Northcott PA, Dalton J, Fraga C, Ellison D, Angers S, Taylor MD and Kenney AM: YAP1 is amplified and up-regulated in hedgehog-associated medulloblastomas and mediates Sonic hedgehog-driven neural precursor proliferation. Genes Dev 23: 2729-2741, 2009.

99. Lin YT, Ding JY, Li MY, Yeh TS, Wang TW and Yu JY: YAP regulates neuronal differentiation through Sonic hedgehog signaling pathway. Exp Cell Res 318: 1877-1888, 2012.

100. Hayashi S, Tamura K and Yokoyama H: Yap1, transcription regulator in the Hippo signaling pathway, is required for Xenopus limb bud regeneration. Dev Biol 388: 57-67, 2014.

101. Hsu TH, Yang CY, Yeh TH, Huang YC, Wang TW and Yu JY: The Hippo pathway acts downstream of the Hedgehog signaling to regulate follicle stem cell maintenance in the Drosophila ovary. Sci Rep 7: 4480, 2017.

102. Machado MV, Michelotti GA, Pereira TA, Xie G, Premont R, Cortez-Pinto H and Diehl AM: Accumulation of duct cells with activated YAP parallels fibrosis progression in non-alcoholic fatty liver disease. J Hepatol 63: 962-970, 2015.

103. Yimlamai D, Christodoulou C, Galli GG, Yanger K Pepe-Mooney B, Gurung B, Shrestha K, Cahan P, Stanger BZ and Camargo FD: Hippo pathway activity influences liver cell fate. Cell 157: 1324-1338, 2014

104. Cotton JL, Li Q, Ma L, Park JS, Wang J, Ou J, Zhu LJ, Ip YT, Johnson RL and Mao J: YAP/TAZ and hedgehog coordinate growth and patterning in gastrointestinal mesenchyme. Dev Cell 43: 35-47.e4, 2017.

105. Heng BC, Zhang X, Aubel D, Bai Y, Li X, Wei Y, Fussenegger M and Deng X: Role of YAP/TAZ in cell lineage fate determination and related signaling pathways. Front Cell Dev Biol 8: 735 , 2020.

106. Blanpain $\mathrm{C}$ and Fuchs E: Epidermal homeostasis: A balancing act of stem cells in the skin. Nat Rev Mol Cell Biol 10: 207-217, 2009.

107. Simpson CL, Patel DM and Green KJ: Deconstructing the skin: Cytoarchitectural determinants of epidermal morphogenesis. Nat Rev Mol Cell Biol 12: 565-580, 2011.

108. Watt FM, Estrach S and Ambler CA: Epidermal Notch signalling: Differentiation, cancer and adhesion. Curr Opin Cell Biol 20: 171-179, 2008

109. Totaro A, Castellan M, Battilana G, Zanconato F, Azzolin L, Giulitti S, Cordenonsi M and Piccolo S: YAP/TAZ link cell mechanics to Notch signalling to control epidermal stem cell fate. Nat Commun 8: 15206, 2017.

110. Low BC, Pan CQ, Shivashankar GV, Bershadsky A, Sudol M and Sheetz M: YAP/TAZ as mechanosensors and mechanotransducers in regulating organ size and tumor growth. FEBS Lett 588: 2663-2670, 2014

111. Piccolo S, Cordenonsi M and Dupont S: Molecular pathways: YAP and TAZ take center stage in organ growth and tumorigenesis. Clin Cancer Res 19: 4925-4930, 2013.

112. Hayashi S, Yokoyama H and Tamura K: Roles of Hippo signaling pathway in size control of organ regeneration. Dev Growth Differ 57: 341-351, 2015.
113. Ramos A and Camargo FD: The Hippo signaling pathway and stem cell biology. Trends Cell Biol 22: 339-346, 2012.

114. Mo JS, Park HW and Guan KL: The Hippo signaling pathway in stem cell biology and cancer. EMBO Rep 15: 642-656, 2014.

115. Hans C: Wnt/beta-catenin signaling in development and disease. Cell 127: 469-480, 2006.

116. Niehrs C and Acebron SP: Mitotic and mitogenic Wnt signalling. EMBO J 31: 2705-2713, 2012.

117. Piccolo S, Dupont S and Cordenonsi M: The biology of YAP/TAZ: Hippo signaling and beyond. Physiol Rev 94 1287-1312, 2014.

118. Azzolin L, Panciera T, Soligo S, Enzo E, Bicciato S, Dupont S, Bresolin S, Frasson C, Basso G, Guzzardo V, et al: YAP/TAZ incorporation in the $\beta$-catenin destruction complex orchestrates the Wnt response. Cell 158: 157-170, 2014.

119. Park HW, Kim YC, Yu B, Moroishi T, Mo JS, Plouffe SW, Meng Z, Lin KC, Yu FX, Alexander CM, et al: Alternative Wnt signaling activates YAP/TAZ. Cell 162: 780-794, 2015.

120. Chen X, Yuan W, Li Y, Luo J and Hou N: Role of Hippo-YAP1/TAZ pathway and its crosstalk in cardiac biology. Int J Biol Sci 16: 2454-2463, 2020.

121. Sato N, Meijer L, Skaltsounis L, Greengard P and Brivanlou AH: Maintenance of pluripotency in human and mouse embryonic stem cells through activation of Wnt signaling by a pharmacological GSK-3-specific inhibitor. Nat Med 10: 55-63, 2004.

122. Weston CR and Davis RJ: The JNK signal transduction pathway. Curr Opin Cell Biol 19: 142-149, 2007.

123. Chen F: JNK-induced apoptosis, compensatory growth, and cancer stem cells. Cancer Res 72: 379-386, 2012.

124. Bogoyevitch MA and Kobe B: Uses for JNK: The many and varied substrates of the c-Jun N-terminal kinases. Microbiol Mol Biol Rev 70: 1061-1095, 2006.

125. Kaunas R, Usami S and Chien S: Regulation of stretch-induced JNK activation by stress fiber orientation. Cell Signal 18: 1924-1931, 2006.

126. Codelia VA, Sun G and Irvine KD: Regulation of YAP by mechanical strain through Jnk and Hippo signaling. Curr Biol 24: 2012-2017, 2014

127. Wang L, Luo JY, Li B, Tian XY, Chen LJ, Huang Y, Liu J, Deng D, Lau CW, Wan S, et al: Integrin-YAP/TAZ-JNK cascade mediates atheroprotective effect of unidirectional shear flow. Nature 540: 579-582, 2016

128. Plouffe SW, Hong AW and Guan KL: Disease implications of the Hippo/YAP pathway. Trends Mol Med 21: 212-222, 2015.

129. Martinez B, Yang Y, Harker DMR, Farrar C, Mukundan H, Nath $\mathrm{P}$ and Mascareñas D: YAP/TAZ related BioMechano signal transduction and cancer metastasis. Front Cell Dev Biol 7: 199, 2019.

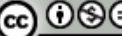

This work is licensed under a Creative Commons Attribution-NonCommercial-NoDerivatives 4.0 International (CC BY-NC-ND 4.0) License. 